\title{
Evaluation of diaphragm ultrasound in predicting extubation outcome in mechanically ventilated patients with COPD
}

\author{
Xia Zhang ${ }^{1}$ • Jing Yuan ${ }^{2} \cdot$ Yong Zhan ${ }^{2} \cdot$ Jingyi $\mathrm{Wu}^{2} \cdot$ Biaohu Liu ${ }^{1} \cdot$ Peng Zhang ${ }^{2} \cdot$ Tao $\mathrm{Yu}^{2} \cdot$ Zhen Wang $^{2}$. \\ Xiaogan Jiang ${ }^{2} \cdot$ Weihua Lu $^{2}$
}

Received: 8 July 2019 / Accepted: 9 October 2019 / Published online: 6 November 2019

(C) Royal Academy of Medicine in Ireland 2019

\begin{abstract}
Background To explore the value of the right hemi-diaphragmatic excursion (DE) and its variation in predicting extubation outcome in mechanically ventilated patients with COPD.

Methods All included patients with COPD received mechanical ventilation (MV) and were ready to wean from MV. After patients passed the $30 \mathrm{~min}$ spontaneous breathing trail (SBT), extubation was considered to be feasible, and the right DE measured by ultrasound at $0 \mathrm{~min}, 5 \mathrm{~min}$, and $30 \mathrm{~min}$ of $\mathrm{SBT}$ were named as $\mathrm{DE}_{0}, \mathrm{DE}_{5}$, and $\mathrm{DE}_{30}$, respectively.

Results Twenty-five patients succeeded extubation; 12 patients failed. The area under receiver operator characteristic curve $\left(\mathrm{AUC}_{\mathrm{ROC}}\right.$ ) of $\mathrm{DE}_{30}$ and $\triangle \mathrm{DE}_{30-5}$ (the variation between 30 and $5 \mathrm{~min}$ ) were 0.762 and 0.835 ; a cutoff value of $\mathrm{DE}_{30}>$ $1.72 \mathrm{~cm}$ and $\Delta D_{30-5}>0.16 \mathrm{~cm}$ were associated with a successful extubation with a sensitivity of $76 \%$ and $84 \%$, a specificity of $75 \%$ and $83.3 \%$, respectively. The predictive probability equation of the $\mathrm{DE}_{30}$ plus $\Delta \mathrm{DE}_{30-5}$ was $P=1 /\left[1+\mathrm{e}^{-(-5.625+}\right.$ $\left.17.689 \times \Delta \mathrm{DE}_{30-5}+1.802 \times \mathrm{DE}_{30}{ }^{\prime}\right]$, a cutoff value of $P>0.626$ was associated with a successful extubation with the $\mathrm{AUC}_{\mathrm{ROC}}$ of 0.867 , a sensitivity of $92 \%$, and a specificity of $83.3 \%$.

Conclusion The combination of $\mathrm{DE}_{30}$ and $\Delta \mathrm{DE}_{30-5}$ could improve the predictive value and could be used as the predictor of extubation outcome in mechanically ventilated patients with COPD.
\end{abstract}

Keywords COPD $\cdot$ Diaphragm $\cdot$ Ultrasonography $\cdot$ Ventilator weaning

\section{Introduction}

Mechanical ventilation (MV) is an important and effective treatment for patients with respiratory failure. More than $40 \%$ patients in intensive care units (ICU) require MV as a part of their process of care [1]. Clinicians in ICU are often challenged with the decisions regarding when and how to wean critically ill patients from MV. Weaning from MV is

Xia Zhang, Jing Yuan and Yong Zhan contributed equally to this work.

Jingyi Wu

yjsicu@163.com

1 Department of Ultrasound, The First Affiliated Hospital of Wannan Medical College, No. 2 Zheshan West Road, Wuhu 241001, Anhui Province, China

2 Department of Intensive Care Unit, The First Affiliated Hospital of Wannan Medical College, No. 2 Zheshan West Road,

Wuhu 241001, Anhui Province, China initiated as early as possible to avoid the complications associated with prolonged ventilation, such as ventilator-induced diaphragmatic dysfunction (VIDD). However, clinicians have to balance the benefits of early extubation with the risk of failure extubation and reintubation, while reintubation increases risk of hospital acquired pneumonia by 8 times, death by $6-12$ times [2].

COPD is characterized by incomplete reversible airflow limitation; the respiratory muscle has high workload for a long time. The diaphragm, as the major respiratory muscle, is responsible for approximately $60-80 \%$ of the workload [3]. As a result, the diaphragmatic function plays a critical role in weaning from MV. Consequently, the thinning diaphragm, descending movement, and impaired contractility easily develop VIDD in patients with COPD due to systemic inflammatory response, oxidative stress, malnutrition, and chronic hypoxia [4]. In fact, the previous studies have demonstrated a majority of mechanically ventilated patients spent a staggering $40 \%$ of the time devoted to weaning from MV in the ICU, $60 \%$ for COPD [5-7]. In general, the evaluation of diaphragmatic 
function was common in mechanically ventilated patients in the ICU. Several traditional variables for evaluating diaphragmatic function have been used in clinical practice, such as maximum inspiratory, expiratory pressure, and maximum trans-diaphragmatic pressure. But these variables presented some limitations that were invasive and dependent greatly on patient's cooperation, which make them to be put into difficult practice in the ICU. Other methods of assessing diaphragmatic function showed also disadvantages, like radiolesion, movement artifacts, and non-continuity, as in the case of chest Xrays, or were difficult to be carried out at the bedside, such as computed tomography and magnetic resonance imaging [8].

Ultrasonography has raised great interest as a noninvasive, easily available, and high reproducible method in evaluation of diaphragmatic function. Along with the growing use of ultrasonography in the ICU in recent years, it could be used to observe the morphology of the diaphragm, thus to evaluate diaphragmatic function and spontaneous breathing ability [9-11]. The previous studies have showed that the DE measured by ultrasound could be used to assess respiratory effort, and while diaphragmatic thickening fraction was shown to be correlated strongly with diaphragm strength and ventilator support level, the right DE assessed by ultrasound was more reliable, more feasible, and more repeatable [12-18]. Therefore, the aim of our study was to explore the value of the right DE and its variation assessed by ultrasound in predicting extubation outcome in mechanically ventilated patients with COPD.

\section{Material and methods}

\section{Study subjects and selection criteria}

This prospective observation study was performed from January 2014 to August 2018 in the ICU of the First Affiliated Hospital of Wannan Medical College. All patients with acute respiratory failure due to COPD and necessitating MV were included in the study. The study protocol was approved by the ethics committee of the First Affiliated Hospital of Wannan Medical College, and informed consent was obtained from each patient's family.

Inclusion criteria: (1) Global strategy for the diagnosis, management, and prevention of chronic obstructive pulmonary disease and practical guidelines for MV worked out by Chinese Society of Critical Care Medicine were used as the diagnostic criteria [2] [19]. (2) No less than $24 \mathrm{~h}$ for mechanical ventilation. (3) Aged over 18 years old. (4) The patients were ready to wean from MV.

Exclusion criteria: (1) Unstable hemodynamics. (2) Without spont breath or unstable respiratory. (3) Less than $24 \mathrm{~h}$ for MV. (4) Mental disorders or cognitive impairment. (5) Advanced tumor. (6) Thoracic deformity.

\section{Methods}

\section{Study protocol}

Patients were selected by inclusion criteria and exclusion criteria. Clinicians took charge of the patient's treatment including spontaneous breathing trail (SBT) and extubation. After patients passed the 30-min SBT, extubation was considered to be feasible. During the SBT, diaphragmatic movement was examined and recorded by the ultrasound physician (all images of ultrasound were saved, and measurements were repeated again.). In the whole process of SBT, infusion speed of drugs and other treatment remained unchanged. The patient was monitored by the ECG monitor to record the changes of heart rate (HR), mean arterial pressure (MAP), respiration rate $(\mathrm{RR})$, and pulse oxygen saturation $\left(\mathrm{S}_{\mathrm{PO} 2}\right)$, and to observe the change of mental status. The patients were divided into successful extubation group and failure extubation group according to extubation outcome. General information and various weaning parameters of patients were collected prospectively, such as fraction of inspired oxygen $\left(\mathrm{F}_{\mathrm{iO} 2}\right)$, partial pressure of arterial oxygen $\left(\mathrm{P}_{\mathrm{aO} 2}\right)$, and partial pressure of arterial carbon dioxide $\left(\mathrm{P}_{\mathrm{aCO} 2}\right)$. The efficacy (sensitivity, specificity, etc.) of DE and its changes assessed by ultrasound in predicting extubation outcome were calculated and compared. Attending clinicians were blind to the ultrasound results.

The criteria for successful extubation: successful extubation was defined as the ability to maintain spontaneous breathing for at least $48 \mathrm{~h}$, without any ventilatory support. In contrast, failure extubation was defined as the reconnection to ventilator (invasive or noninvasive) within $48 \mathrm{~h}$ due to respiratory failure or other reasons [10, 20]. Extubation and the reconnection to ventilator were all based on SBT results and physicians' decision.

\section{Spontaneous breathing trail}

Pressure support ventilation with a support pressure of 5-8 $\mathrm{cmH}_{2} \mathrm{O}$ and a PEEP level of $\leq 5 \mathrm{cmH}_{2} \mathrm{O}$ were employed for $30 \mathrm{~min}$ in the process of SBT.

Patients were assessed daily until the factors which developed respiratory failure were controlled or reversed. The criteria for SBT initiation were as follows: (1) clear consciousness (aroused, Glasgow Coma Score $\geq 13$ ); (2) without dyspnea, 10 breaths/min (bpm) $\leq \mathrm{RR} \leq 35$ bpm; (3) $\mathrm{F}_{\mathrm{iO} 2} \leq 0.35$, PEEP $\leq 5 \mathrm{cmH}_{2} \mathrm{O}, \mathrm{P}_{\mathrm{aO} 2} / \mathrm{F}_{\mathrm{iO} 2} \geq 150 \mathrm{mmHg}, \mathrm{PH}>7.30$, and $\mathrm{P}_{\mathrm{aCO} 2}$ reached the level of remission; (4) hemodynamic stability, and without myocardial ischemia, absence of severe hypotension, in the absence of any vasopressors or small dose (dopamine $<$ $5 \mathrm{ug} /(\mathrm{kg} \mathrm{min})$ or norepinephrine $<0.1 \mathrm{ug} /(\mathrm{kg} \mathrm{min})$; (5) no apparent acid; (6) hemoglobin $>80 \mathrm{~g} / \mathrm{L}$; (7) subjective clinical evaluation: clinicians considered that patients have sufficient airway protection and could be weaned [2]. 
The criteria for SBT termination were as follows: (1) RR > 35 or $<10 \mathrm{bpm}$ for $5 \mathrm{~min}$ or involving auxiliary respiratory muscles; (2) $\mathrm{S}_{\mathrm{PO} 2}<88 \%, \mathrm{P}_{\mathrm{aO} 2} / \mathrm{F}_{\mathrm{iO} 2} \leq 150 \mathrm{mmHg}, \mathrm{PH} \leq 7.30$; (3) $\mathrm{HR}>140 \mathrm{bpm}$ or continuous polycardia, faster or slower than basic heart rate by $20 \%$; (4) systolic blood pressure $>180$ or $<90 \mathrm{mmHg}$; (5) change in mental status (such as somnolence, coma); (6) new myocardial ischemia. When one of the abovementioned criteria was reached, patients were reconnected and evaluated every day until successful SBT [2].

\section{Diaphragmatic ultrasound}

All patients were evaluated in semi-recumbent position (with elevating the head of the bed to $30^{\circ}$ ). First, the diaphragm was visualized by placing the $2-5 \mathrm{MHz}$ convex probe to the right subcostal area between the anterior axillary and the midclavicular lines, the probe was directed to the head, with the right lobe of liver as a window, and the optimal images of diaphragm were captured by adjusting the probe direction. The right hemi-diaphragm was observed by twodimensional ultrasonography until its movement was stable and its image was clear. Then, M-mode was used to record the movement of the diaphragm during tidal breathing when the sampling line and diaphragm were as vertical as possible (not $<70^{\circ}$ ). After the first data was taken, with the position markers fixed on the skin surface, the average of the three measurements was recorded.

\section{Measured variables}

General information such as patient name, gender, age, acute physical and chronic health score II (APACHE II), and MV time before admission were all recorded. The data was measured from the first respiratory cycle at $0 \mathrm{~min}$ after SBT. The $\mathrm{DE}$ at $0 \mathrm{~min}, 5 \mathrm{~min}$, and $30 \mathrm{~min}$ of SBT was respectively named as $\mathrm{DE}_{0}, \mathrm{DE}_{5}$, and $\mathrm{DE}_{30}$. The variation of right $\mathrm{DE}$ between each time point was named as $\Delta \mathrm{DE}_{30-5}$ and
$\Delta \mathrm{DE}_{30-0}$. The $\mathrm{P}_{\mathrm{aO} 2} / \mathrm{F}_{\mathrm{iO} 2}(\mathrm{P} / \mathrm{F})$ and $\mathrm{P}_{\mathrm{aCO} 2}$ were observed and recorded at $0 \mathrm{~min}$ and $30 \mathrm{~min}$ after $\mathrm{SBT}$, besides $\mathrm{HR}$, tidal volume $(\mathrm{Vt}), \mathrm{RR}, \mathrm{MAP}$, rapid shallow breathing index (RSBI), DE of each time point after SBT.

$$
\begin{aligned}
\Delta \mathrm{DE}_{30-5} & =\mathrm{DE}_{30}-\mathrm{DE}_{5} \\
\Delta \mathrm{DE}_{30-0} & =\mathrm{DE}_{30}-\mathrm{DE}_{0}
\end{aligned}
$$

\section{Statistical analysis}

All statistical analyses were performed using SPSS 22.0. Data were presented as the mean \pm standard deviation $(\chi(-) \pm s)$ or median and interquartile range when appropriate. Fisher exact test was used to compare categorical data (gender). Student's $t$ test was used to compare differences of continuous variables between the two groups. Mann-Whitney $U$ tests were used to compare differences of MV time between the two groups. Receiver operator characteristic curves (ROC curves) analysis and binary logistic regression analysis were used to evaluate the predictive value of diaphragmatic parameters. A $P$ value $<$ 0.05 was considered statistically significant.

\section{Results}

\section{General information}

During the study period, 4 patients were excluded from the study because of poor ultrasound measurement images, while 37 patients were included in this study. Of the 37 patients, 12 patients $(32.0 \%)$ failed extubation after SBT, as shown in Fig. 1. There was no statistical difference in age, gender, APACHE II score, and MV time between the two groups $(P>0.05)$, as shown in Table 1.

Fig. 1 Flow chart of patient selection

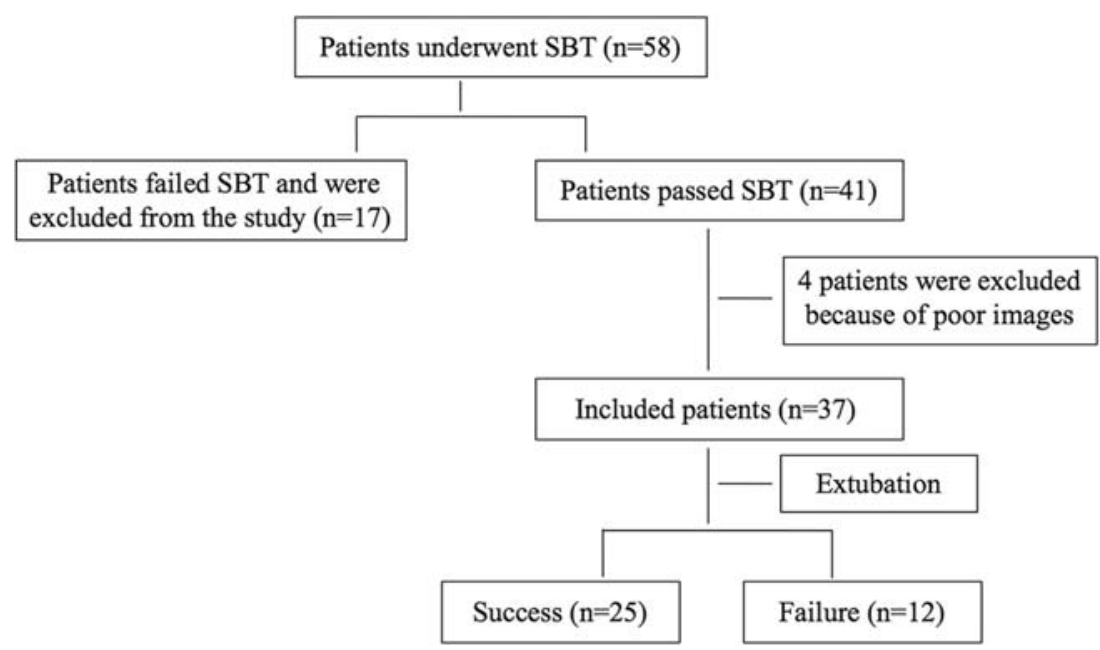


Table 1 Patients characteristics between the two groups

\begin{tabular}{|c|c|c|c|c|c|c|}
\hline \multirow[t]{2}{*}{ Groups } & \multirow[t]{2}{*}{ Number } & \multicolumn{2}{|c|}{ Gender } & \multirow[t]{2}{*}{ Age (years) } & \multirow[t]{2}{*}{ APACHE II } & \multirow{2}{*}{$\begin{array}{l}\text { MV time } \\
\text { (h) }\end{array}$} \\
\hline & & $\begin{array}{l}\mathrm{Ma} \\
\text { fem }\end{array}$ & & & & \\
\hline Success & 25 & 18 & 7 & $74.5 \pm 7.5$ & $14.9 \pm 5.7$ & $77(46,108)$ \\
\hline Failure & 12 & 9 & 3 & $73.5 \pm 8.6$ & $17.1 \pm 4.8$ & $88(63,122)$ \\
\hline$P$ & & & 47 & 0.715 & 0.264 & 0.496 \\
\hline
\end{tabular}

APACHE II acute physiology and chronic health status score II

\section{Comparison of respiration parameters}

At all time points of $\operatorname{SBT}(0,5$, and $30 \mathrm{~min})$, there was no significant difference in $\mathrm{HR}$ and MAP between the two groups $(P>0.05)$. The difference of RR, Vt, RSBI, $\mathrm{P}_{\mathrm{aCO} 2}, \mathrm{P} / \mathrm{F}$, and $\mathrm{DE}$ between the two groups was not significant at $0 \mathrm{~min}$ time point $(P>0.05)$. However, at $5 \mathrm{~min}$ and $30 \mathrm{~min}$ time points, the RR and RSBI of patients in the successful extubation group were significantly lower, $\mathrm{Vt}$ and $\mathrm{DE}$ were significantly higher $(P<0.05)$. In addition, at $30 \mathrm{~min}$ time point, the $\mathrm{P} / \mathrm{F}$ of patients was significantly higher in the successful extubation group $(P<0.05)$, while the difference of $\mathrm{P}_{\mathrm{aCO} 2}$ was not significant between the two groups $(P>0.05)$, as shown in Table 2.

\section{Comparison of $\triangle \mathrm{DE}$ at each time points}

As shown in Table 3, $\Delta \mathrm{DE}_{5-0}$ between the two groups has no significant difference $(P>0.05)$. Compared with the failure extubation group, $\triangle \mathrm{DE}_{30-0}$ and $\triangle \mathrm{DE}_{30-5}$ were significantly higher in the successful extubation group $(P<0.05)$.

\section{Comparison of the predictive value}

A ROC curve analysis was used to assess the accuracy of diaphragmatic parameters in predicting extubation outcome.
As shown in Table 4, a cutoff value of $\mathrm{RSBI}_{30}$ less than 73.9 $\mathrm{bpm} / \mathrm{L}$ was associated with a successful extubation with the $\mathrm{AUC}_{\mathrm{ROC}}$ of 0.815 , a sensitivity of $75 \%$, a specificity of $80 \%$, a positive predictive value (PPV) of $64.3 \%$, and a negative predictive value (NPV) of $87.0 \%$. A cutoff value of $\mathrm{DE}_{30}$ more than $1.72 \mathrm{~cm}$ was associated with a successful extubation with the $\mathrm{AUC}_{\mathrm{ROC}}$ of 0.762 , a sensitivity of $76 \%$, a specificity of $75 \%$, a PPV of $86.4 \%$, and a NPV of $60 \%$. Similarly, the $\mathrm{AUC}_{\mathrm{ROC}}$ was 0.693 for $\mathrm{DE}_{5}$, and a $\mathrm{DE}_{5}$ value of $>1.63 \mathrm{~cm}$ predicted successful extubation with a sensitivity of $64 \%$, a specificity of $75 \%$, a PPV of $84.2 \%$, and a NPV of $50 \%$ (Fig. 2). Our study presented the variation of DE between 5 and 30 minutes of SBT was named as $\triangle \mathrm{DE}_{30-5}$; a cutoff value of $\Delta \mathrm{DE}_{30-5}>0.16 \mathrm{~cm}$ was associated with a successful extubation with the $\mathrm{AUC}_{\mathrm{ROC}}$ of 0.835 , a sensitivity of $84 \%$, a specificity of $83.3 \%$, a PPV of $91.3 \%$, and a NPV of $71.4 \%$. Likewise, the $\mathrm{AUC}_{\mathrm{ROC}}$, sensitivity, specificity, PPV, and NPV of $\mathrm{DE}_{30-0}$ were $0.83,40 \%, 100 \%, 100 \%$, and $44.4 \%$, respectively (Fig. 3).

The positive predictive value was $94.7 \%$ when both $\mathrm{DE}_{30}$ and $\triangle \mathrm{DE}_{30-5}$ were positive. The negative predictive value was $80.0 \%$ when both $\mathrm{DE}_{30}$ and $\triangle \mathrm{DE}_{30-5}$ were negative. When the $\mathrm{DE}_{30}$ plus $\Delta \mathrm{DE}_{30-5}$ were used to predict extubation outcome, the predictive probability equation obtained by binary logistic regression analysis was $P=1 /\left[1+\mathrm{e}^{-(-5.625+}\right.$ $\left.\left.17.689 \times \Delta \mathrm{DE}_{30-5}+1.802 \times \mathrm{DE}_{30}\right)\right]$, a cutoff value $P>0.626$ was associated with a successful extubation with the $\mathrm{AUC}_{\mathrm{ROC}}$ of 0.867 , a sensitivity of $92 \%$, a specificity of $83.3 \%$, a PPV of $92 \%$, and a NPV of $83.3 \%$ (Fig. 4).

\section{Discussion}

This study demonstrated that the $\mathrm{DE}_{30}$ and $\Delta \mathrm{DE}_{30-5}$ could be used to predict extubation outcome in patients with COPD. The combination of two indicators could improve the predictive value.

Table 2 Comparison of respiration parameters between the two groups during SBT

\begin{tabular}{|c|c|c|c|c|c|c|c|c|c|}
\hline Group & $n$ & HR (bpm) & MAP (mmHg) & RR (bpm) & $\mathrm{Vt}(\mathrm{ml})$ & RSBI (bpm/L) & $\mathrm{DE}(\mathrm{cm})$ & $\mathrm{P}_{\mathrm{aCO} 2}(\mathrm{mmHg})$ & $\mathrm{P} / \mathrm{F}(\mathrm{mmHg})$ \\
\hline Success & 25 & & & & & & & & \\
\hline $0 \mathrm{~min}$ & & $94.6 \pm 15.1$ & $88.3 \pm 8.4$ & $19.1 \pm 3.0$ & $382 \pm 37$ & $51.2 \pm 12.9$ & $1.18 \pm 0.34$ & $39.3 \pm 3.2$ & $268 \pm 23$ \\
\hline $5 \mathrm{~min}$ & & $101.1 \pm 17.8$ & $93.3 \pm 14.0$ & $24.2 \pm 4.1$ & $353 \pm 39$ & $70.4 \pm 19.0$ & $1.75 \pm 0.34$ & & \\
\hline $30 \mathrm{~min}$ & & $97.2 \pm 16.5$ & $92.8 \pm 9.9$ & $21.6 \pm 3.5$ & $367 \pm 38$ & $60.3 \pm 15.8$ & $1.98 \pm 0.36$ & $48.2 \pm 5.4$ & $243 \pm 20$ \\
\hline Failure & 12 & & & & & & & & \\
\hline $0 \mathrm{~min}$ & & $99.6 \pm 15.1^{\bullet}$ & $89.8 \pm 7.4^{\bullet}$ & $20.5 \pm 2.7^{\bullet}$ & $361 \pm 37^{\bullet}$ & $57.9 \pm 12.2^{\bullet}$ & $0.97 \pm 0.27^{\bullet}$ & $38.6 \pm 4.5^{\bullet}$ & $257 \pm 26^{\bullet}$ \\
\hline $5 \mathrm{~min}$ & & $109.9 \pm 14.7^{\Delta}$ & $98.6 \pm 11.0^{\wedge}$ & $26.7 \pm 2.2^{\Delta}$ & $325 \pm 36^{\Delta}$ & $83.7 \pm 14.0^{\Delta}$ & $1.58 \pm 0.28^{\Delta}$ & & \\
\hline $30 \mathrm{~min}$ & & $107.3 \pm 14.1^{\text {" }}$ & $96.8 \pm 10.3^{\mathbf{m}}$ & $25.8 \pm 2.8^{\square}$ & $331 \pm 36^{\square}$ & $79.5 \pm 14.8^{\square}$ & $1.64 \pm 0.30^{\square}$ & $50.2 \pm 5.7^{\bullet}$ & $226 \pm 25^{\square}$ \\
\hline
\end{tabular}

$H R$, heart rate; $M A P$, mean arterial pressure; $R R$, respiratory rate; $V t$, tidal volume; $R S B I$, rapid shallow breathing index; $D E$, diaphragm excursion; $P_{a C O 2}$, partial pressure of arterial carbon dioxide; $P / F, \mathrm{P}_{\mathrm{aO} 2} / \mathrm{F}_{\mathrm{iO} 2} ;{ }^{\bullet} P>0.05$ compared with the group of success at 0 min; ${ }^{\wedge} P>0.05,{ }^{\Delta} P<0.05$ compared with the group of success at $5 \mathrm{~min} ;{ }^{-} P>0.05,{ }^{口} P<0.05$ compared with the group of success at $30 \mathrm{~min}$ 
Table 3 Comparison of $\triangle \mathrm{DE}$ between the two groups during SBT

\begin{tabular}{lllll}
\hline Group & Number & $\Delta \mathrm{DE}_{5-0}(\mathrm{~cm})$ & $\Delta \mathrm{DE}_{30-5}(\mathrm{~cm})$ & $\Delta \mathrm{DE}_{30-0}(\mathrm{~cm})$ \\
\hline Success & 25 & $0.570 \pm 0.109$ & $0.224 \pm 0.070$ & $0.794 \pm 0.137$ \\
Failure & 12 & $0.528 \pm 0.104$ & $0.135 \pm 0.073$ & $0.663 \pm 0.108$ \\
$t$ & & 1.112 & 3.573 & 2.882 \\
$P$ & & 0.281 & 0.001 & 0.007 \\
\hline
\end{tabular}

$\Delta \mathrm{DE}_{30-0}=\mathrm{DE}_{30}-\mathrm{DE}_{0}$, and so on

The diaphragm is the major respiratory muscle; diaphragmatic dysfunction is responsible for difficult weaning from MV and prolonged MV which in turn may promote diaphragmatic dysfunction named as VIDD [20-23]. MV for 6-12 h can result in significant diaphragmatic atrophy or diaphragmatic dysfunction, as showed by animal studies [24, 25]. Therefore, diaphragmatic dysfunction can interact with MV, and it is time-dependent increase in diaphragmatic dysfunction in patients with the increase of MV time [26, 27]. Diaphragmatic dysfunction has a relatively higher incidence in patients with COPD undergoing MV [28]. Consequently, the prompt and accurate evaluation of the diaphragmatic function is crucial to successful weaning from MV in patients with COPD. SBT has been usually employed to predict extubation outcome. Even if patients passed SBT, the rate of failure extubation could still reach approximately $25 \%$ $[11,29,30]$. As a result, it will be very valuable to seek an easily available and accurate indicator to predict extubation outcome and improve survival rate of patients in the ICU.

Along with the growing use of ultrasonography in the ICU in recent years, both diaphragmatic thickening fraction and diaphragmatic excursion (DE) could be used as predictors of weaning from MV [10, 11, 13]. However, recent studies shown that DE was closely correlated with the first second exhalation, lung volume, residual volume, minute ventilation, and maximum inspiratory volume $[14,31]$. Moreover, DE correlated well with trans-diaphragmatic pressure [15]. DE assessed by ultrasound was more accurate than diaphragmthickening fraction in predicting successful weaning from MV [16]. Accordingly, DE assessed by ultrasound could evaluate well-diaphragmatic function. In addition, the right DE was usually easier to be observed, while the descending lung, bowel, and gas on the left side often interfered with the evaluation of diaphragmatic function during inspiration. Furthermore, descending diaphragm was more susceptible to interference from the surrounding intestine in patients with COPD. Previous studies suggested ultrasound measured successfully the right DE of 195 patients in 210 patients with a 93\% success rate, while the success rate of the left DE was only $21 \%[17,18]$. Therefore, the right DE and its variation were assessed by ultrasound in this study.

The rate of failure extubation was $32 \%$ in our study, slightly higher than previous reports. Some reasons maybe (1) patients who were included all had COPD and acute respiratory failure. They were prone to diaphragmatic dysfunction. (2) The patients in this study were relatively older. The aged patients were susceptible to weaning due to descended thoracic compliance and weak respiratory muscle. As a result, the rate of successful extubation was negatively affected.

$\mathrm{DE}$ is a surrogate of diaphragmatic contractility. Normal data of DE is still lacking in patients with MV, and it has a great variation in different respiratory status among different studies $[18,32]$. In this study, the range of DE measured by ultrasound was $0.68-2.78 \mathrm{~cm}$; the DE was significantly higher in the successful extubation than in the failure extubation at the different time of weaning process $(P<0.05)$. Moreover, compared with $\mathrm{DE}_{5}, \mathrm{DE}_{30}$ was more accurate (characterized as higher sensitivity and specificity, larger $\mathrm{AUC}_{\mathrm{ROC}}$ ). The key to the successful extubation is not only the respiratory muscle contractility but also the endurance of the respiratory muscle contraction. Therefore, one measurement often does not sufficiently show the endurance of the respiratory muscle contraction. The variations among each time point for DE may more sufficiently reflect the endurance of diaphragmatic contraction. Our study indicated that compared with $\triangle \mathrm{DE}_{30-0}$, the $\mathrm{AUC}_{\mathrm{ROC}}$ and sensitivity of $\triangle \mathrm{DE}_{30-5}$ were significantly larger and higher, but specificity was lower. Overall, $\triangle \mathrm{DE}_{30}$ -5 was considered to be more accurate in predicting extubation outcome in this study.

Accordingly, our study showed that the positive predictive value was $94.7 \%$ when both indicators were positive, in contrast, the negative predictive value of $80 \%$. When the $\mathrm{DE}_{30}$ plus $\triangle \mathrm{DE}_{30-5}$ was used to predict extubation outcome
Table 4 Comparison of the predictive value of the index for extubation outcome

\begin{tabular}{lllllll}
\hline Index & AUC $_{\text {ROC }}$ & Cutoff & Sensitivity & Specificity & PPV & NPV \\
\hline $\mathrm{RSBI}_{30}$ & 0.815 & $73.9(\mathrm{bpm} / \mathrm{L})$ & $75.0 \%$ & $80.0 \%$ & $64.3 \%$ & $87.0 \%$ \\
$\mathrm{DE}_{5}$ & 0.693 & $1.63(\mathrm{~cm})$ & $64.0 \%$ & $75.0 \%$ & $84.2 \%$ & $50.0 \%$ \\
$\mathrm{DE}_{30}$ & 0.762 & $1.72(\mathrm{~cm})$ & $76.0 \%$ & $75.0 \%$ & $86.4 \%$ & $60.0 \%$ \\
$\Delta \mathrm{DE}_{30-0}$ & 0.745 & $0.83(\mathrm{~cm})$ & $40.0 \%$ & $100 \%$ & $100 \%$ & $44.4 \%$ \\
$\Delta \mathrm{DE}_{30-5}$ & 0.835 & $0.16(\mathrm{~cm})$ & $84.0 \%$ & $83.3 \%$ & $91.3 \%$ & $71.4 \%$ \\
$\mathrm{DE}_{30}$ plus $\triangle \mathrm{DE}_{30-5}$ & 0.867 & 0.626 & $92.0 \%$ & $83.3 \%$ & $92.0 \%$ & $83.3 \%$ \\
\hline
\end{tabular}

$A U C_{R O C}$, area under receiving operating characteristic curve; $P P V$, positive predictive value; $N P V$, negative predictive value 


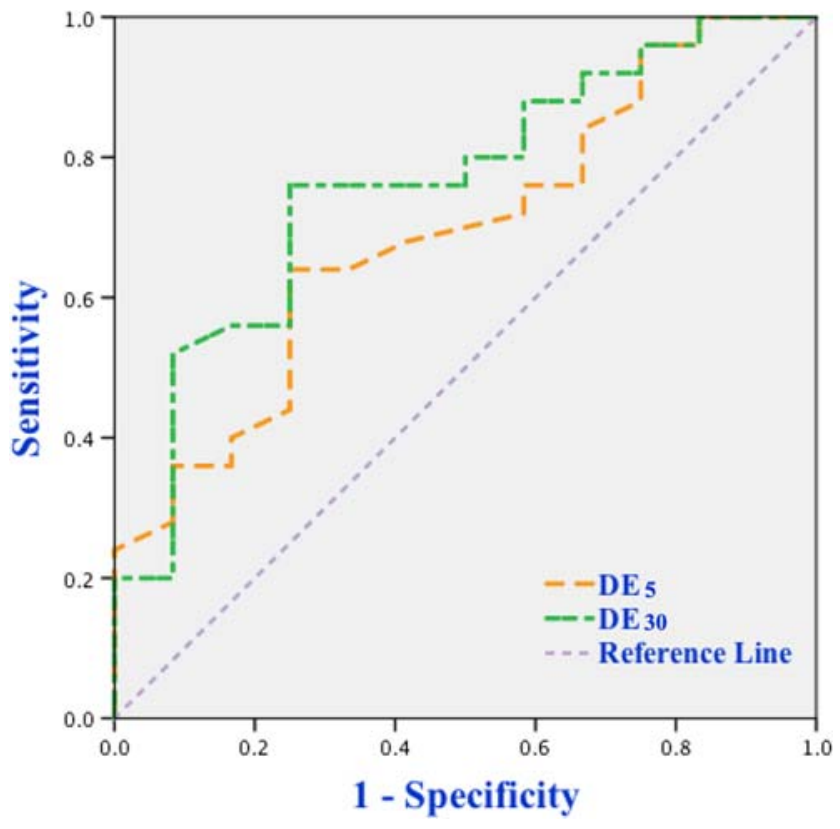

Fig. 2 ROC curves of $\mathrm{DE}_{5}$ and $\mathrm{DE}_{30}$ for predicting extubation outcome

by binary logistic regression analysis, the $\mathrm{AUC}_{\mathrm{ROC}}$ and sensitivity were significantly larger and higher compared with $\triangle \mathrm{DE}_{30-0}$ and $\mathrm{DE}_{30}$. On the whole, $\mathrm{DE}_{30}$ plus $\Delta \mathrm{DE}_{30-5}$ was considered to be more accurate in predicting extubation outcome. Furthermore, this study showed that compared with traditional parameters such as RSBI, $\mathrm{DE}_{30}$ plus $\Delta \mathrm{DE}_{30-5}$ was considered to be more accurate in predicting extubation outcome(the $\mathrm{AUC}_{\mathrm{ROC}}$ and specificity were significantly higher). RSBI reflected effort of all respiratory muscles. So, in presence of diaphragmatic fatigue, accessory muscles

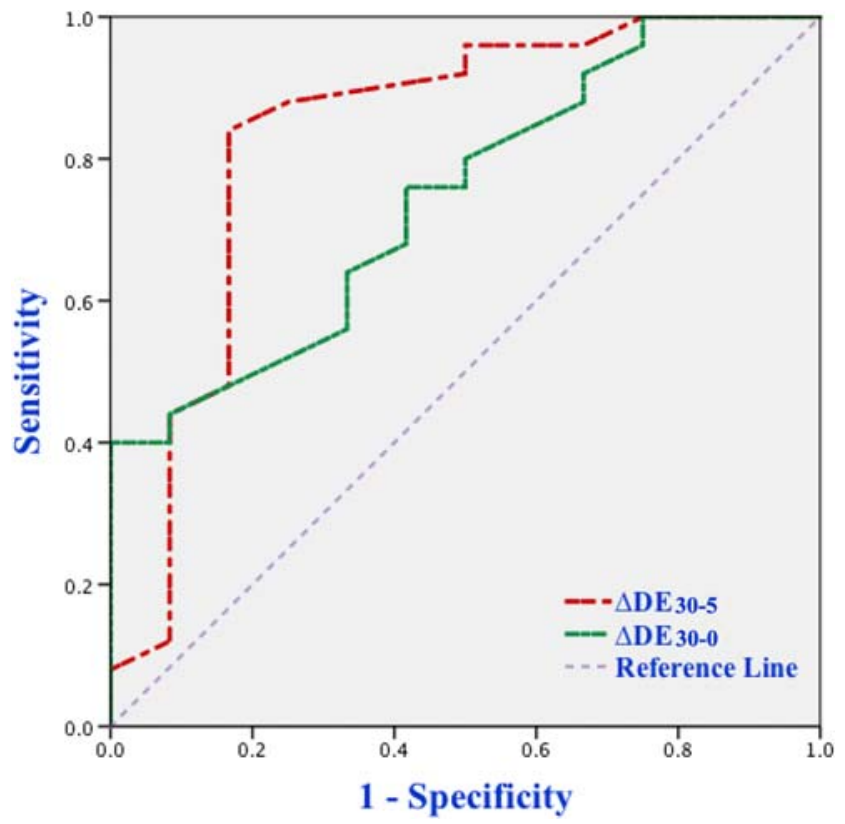

Fig. 3 ROC curves of $\triangle \mathrm{DE}_{30-0}$ and $\Delta \mathrm{DE}_{30-5}$ for predicting extubation outcome

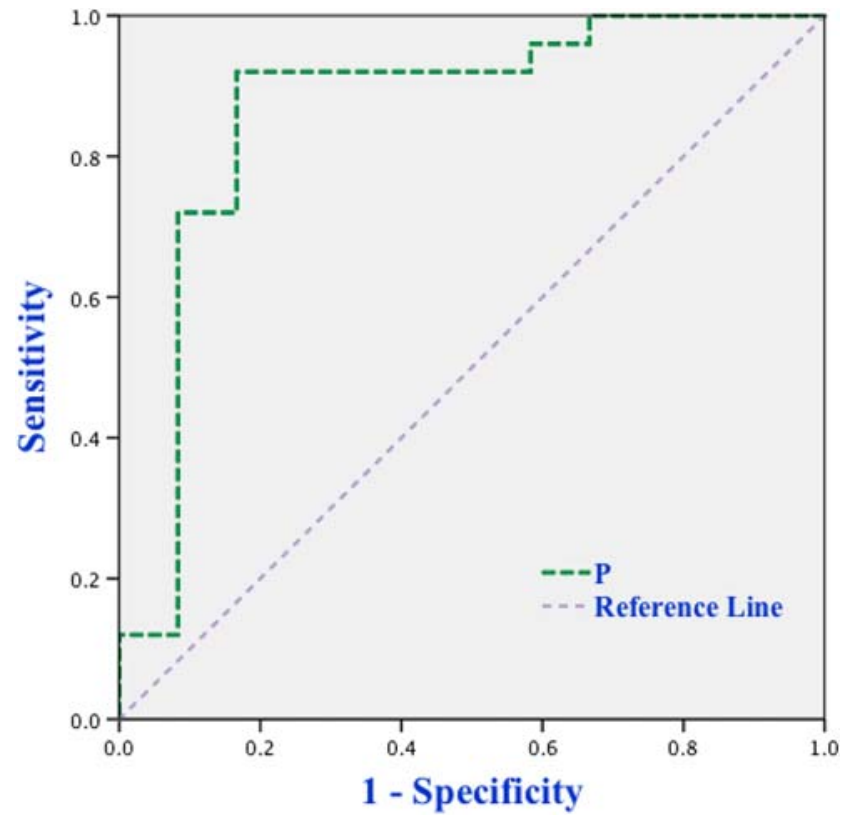

Fig. 4 ROC curve of $\mathrm{P}\left(\mathrm{DE}_{30}\right.$ plus $\left.\Delta \mathrm{DE}_{30-5}\right)$ for predicting extubation outcome

could preserve tidal volume for a short time of SBT but not a long time and thus it was prone to failure extubation despite successfully passing the SBT.

The limitations of this study are as follows: Firstly, cardiac function had not been fully taken into account, which may be responsible for failure extubation. Secondly, the diaphragmatic ultrasound was not operated by two observers at the same time. Thirdly, the left diaphragm was not assessed by ultrasound. The subjects were older COPD patients in this study, and the left hemidiaphragm was frequently obscured by the expanding lung. However, Kim et al.'s study showed that unilateral diaphragm dysfunction was more common than bilateral, and the bilateral evaluation of ultrasound can more accurately represent the diaphragm function [20]. At last, The RR, RSBI, and P/F are also commonly used to predict extubation outcome. When we analyze $\mathrm{DE}_{30}$ combined with these indicators, we found that the predicted value of joint judgment has not been improved significantly (the $\mathrm{AUC}_{\mathrm{ROC}}$ has not been increased). Perhaps because this study is a singlecenter study, the number of cases is a limitation, and the selected patients are older and more severe. Further research was required to enlarge sample number.

\section{Conclusions}

In summary, our study demonstrated that compared with the $\mathrm{DE}_{30}$ and $\Delta \mathrm{DE}_{30-5}$, the combination of $\mathrm{DE}_{30}$ and $\Delta \mathrm{DE}_{30-5}$ could improve the predictive value and could be used as the predictor of extubation outcome in mechanically ventilated patients with COPD. 
Authors' contributions Authors' contributions: X. Z. designed this study, supervised the study, and revised the manuscript. J. W., J. Y., and Y. Z. performed the study, contributed to the collection of data, and participated in writing the manuscript. The other authors were involved in the execution of the study and data collection. All the authors participated in writing the manuscript and in reviewing the final manuscript and approving it for publication.

Funding information This study was supported by the Natural Science Research Project of the Higher Education in Anhui Province (KJ2016A730), the Research Project on Application of Commonweal Technology in Anhui Province (1704f0804048), and the Annual Scientific and Technological Projects of Wuhu City (2012hm35).

\section{Compliance with ethical standards}

The study protocol was approved by the ethics committee of the First Affiliated Hospital of Wannan Medical College, and informed consent was obtained from each patient's family.

Conflict of interest The authors declare that they have no conflict of interest.

\section{References}

1. Lone NI, Walsh TS (2011) Prolonged mechanical ventilation in critically ill patients: epidemiology, outcomes and modelling the potential cost consequences of establishing a regional weaning unit. Crit Care. 15(2):R102

2. [Practical guidelines for mechanical ventilation (2006)]. Zhongguo Wei Zhong Bing Ji Jiu Yi Xue. 2007;19(2):65-72.

3. Ratnovsky A, Elad D (2005) Anatomical model of the human trunk for analysis of respiratory muscles mechanics. Respiratory Physiology \& Neurobiology. 148(3):245-262

4. Agusti A, Soriano JB (2008) COPD as a systemic disease. Copd 5(2):-138

5. Esteban A, Frutos F, Tobin MJ, Alía I, Solsona JF, Valverdú I, Fernández R, de la Cal MA, Benito S, Tomás R (1995) A comparison of four methods of weaning patients from mechanical ventilation. Spanish Lung Failure Collaborative Group. N Engl J Med. 332(6):345-350

6. Esteban A, Anzueto A, Frutos F, Alía I, Brochard L, Stewart TE, Benito S, Epstein SK, Apezteguía C, Nightingale P, Arroliga AC, Tobin MJ, Mechanical Ventilation International Study Group (2002) Characteristics and outcomes in adult patients receiving mechanical ventilation: a 28-day international study. Jama. 287(3): 345-355

7. Esteban A, Ferguson ND, Meade MO, Frutos-Vivar F, Apezteguia C, Brochard L, Raymondos K, Nin N, Hurtado J, Tomicic V, González M, Elizalde J, Nightingale P, Abroug F, Pelosi P, Arabi Y, Moreno R, Jibaja M, D'Empaire G, Sandi F, Matamis D, Montañez AM, Anzueto A, VENTILA Group (2008) Evolution of mechanical ventilation in response to clinical research. Am J Respir Crit Care Med. 177(2):170-177

8. Noh DK, Lee JJ, You JH (2014) Diaphragm breathing movement measurement using ultrasound and radiographic imaging: a concurrent validity. Biomed Mater Eng. 24(1):947-952

9. Goligher EC, Laghi F, Detsky ME, Farias P, Murray A, Brace D, Brochard LJ, Bolz SS, Rubenfeld GD, Kavanagh BP, Ferguson ND (2015) Measuring diaphragm thickness with ultrasound in mechanically ventilated patients: feasibility, reproducibility and validity. Intensive Care Med. 41(4):734
10. Ferrari G, De Filippi G, Elia F et al (2014) Diaphragm ultrasound as a new index of discontinuation from mechanical ventilation. Crit Ultrasound J. 6(1):8

11. Farghaly S, Hasan AA (2017) Diaphragm ultrasound as a new method to predict extubation outcome in mechanically ventilated patients. Aust Crit Care. 30(1):37-43

12. Vetrugno L, Guadagnin GM, Barbariol F, Langiano N, Zangrillo A, Bove T (2019) Ultrasound imaging for diaphragm dysfunction: a narrative literature review. J Cardiothorac Vasc Anesth. 33(9): 2525-2536

13. Liu LX, Su D, Hu ZJ (2017) The value of the excursion of diaphragm tested by ultrosonography to predict weaning from mechanical ventilation in ICU patients. Zhonghua Nei Ke Za Zhi. 56(7):495-499

14. He W, Xu Y (2014) Ultrasound assessment of diaphragm mobility by three different approaches in ventilated patients. Zhonghua Wei Zhong Bing Ji Jiu Yi Xue. 26(2):914-916

15. Lerolle N, Guerot E, Dimassi S et al (2009) Ultrasonographic diagnostic criterion for severe diaphragmatic dysfunction after cardiac surgery. Chest. 135(2):401-407

16. Scheibe N, Sosnowski N, Pinkhasik A, Vonderbank S, Bastian A (2015) Sonographic evaluation of diaphragmatic dysfunction in COPD patients. Int J Chron Obstruct Pulmon Dis 10:1925-1930

17. Boussuges A, Gole Y, Blanc P (2009) Diaphragmatic motion studied by m-mode ultrasonography: methods, reproducibility, and normal values. Chest 135(2):391-400

18. Park GY, Kim SR, Kim YW, Jo KW, Lee EJ, Kim YM, Im S (2015) Decreased diaphragm excursion in stroke patients with dysphagia as assessed by M-mode sonography. Arch Phys Med Rehabil. 96(1):114-121

19. Matamis D, Soilemezi E, Tsagourias M, Akoumianaki E, Dimassi S, Boroli F, Richard JC, Brochard L (2013) Sonographic evaluation of the diaphragm in critically ill patients. Technique and clinical applications. Intensive Care Med 39(5):801-810

20. Kim WY, Suh HJ, Hong SB, Koh Y, Lim CM (2011) Diaphragm dysfunction assessed by ultrasonography: influence on weaning from mechanical ventilation. Crit Care Med 39(12):2627-2630

21. Vassilakopoulos T, Petrof BJ (2004) Ventilator-induced diaphragmatic dysfunction. Am J Respir Crit Care Med. 169(3):336-341

22. Valenzuela VJ, Pinochet UR, Escobar CM et al (2014) Ventilatorinduced diaphragmatic dysfunction. Rev Chil Pediatr. 85(4):491498

23. Hudson MB, Smuder AJ, Nelson WB, Bruells CS, Levine S, Powers SK (2012) Both high level pressure support ventilation and controlled mechanical ventilation induce diaphragm dysfunction and atrophy. Crit Care Med. 40(44):1254-1260

24. Mrozek S, Jung B, Petrof BJ, Pauly M, Roberge S, Lacampagne A, Cassan C, Thireau J, Molinari N, Futier E, Scheuermann V, Constantin JM, Matecki S, Jaber S (2012) Rapid onset of specific diaphragm weakness in a healthy murine model of ventilatorinduced diaphragmatic dysfunction. Anesthesiology .117(3):560567

25. Powers SK, Wiggs MP, Sollanek KJ et al (2013) Ventilator-induced diaphragm dysfunction: cause and effect. Am J Physiol Regul Integr Comp Physiol. 305(5):R464-R477

26. Grosu HB, Lee YI, Lee J, Eden E, Eikermann M, Rose KM (2012) Diaphragm muscle thinning in patients who are mechanically ventilated. Chest. 142(6):1455-1460

27. Marchioni A, Castaniere I, Tonelli R, Fantini R, Fontana M, Tabbì L, Viani A, Giaroni F, Ruggieri V, Cerri S, Clini E (2018) Ultrasound-assessed diaphragmatic impairment is a predictor of outcomes in patients with acute exacerbation of chronic obstructive pulmonary disease undergoing noninvasive ventilation. Crit Care. 22(1):109 
28. Thille AW, Harrois A, Schortgen F, Brun-Buisson C, Brochard L (2011) Outcomes of extubation failure in medical intensive care unit patients. Crit Care Med. 39(12):2612-2618

29. Godard S, Herry C, Westergaard P et al (2016) Practice variation in spontaneous breathing trial performance and reporting. Can Respir J. 2016:9848942

30. Yoo JW, Lee SJ, Lee JD et al (2018) Comparison of clinical utility between diaphragm excursion and thickening change using ultrasonography to predict extubation success. Korean J Intern Med. 33(2): 331-339
31. Rocha FR, Bruggemann AK, Francisco DS et al (2017) Diaphragmatic mobility: relationship with lung function, respiratory muscle strength, dyspnea, and physical activity in daily life in patients with COPD. J Bras Pneumol. 43(1):32-37

32. Bobbia X, Clement A, Claret PG et al (2016) Diaphragmatic excursion measurement in emergency patients with acute dyspnea: toward a new diagnostic tool? Am J Emerg Med. 34(8):1653-1657

Publisher's note Springer Nature remains neutral with regard to jurisdictional claims in published maps and institutional affiliations. 